\title{
Effect of strain rate and temperature on mechanical properties of selected building Polish steels
}

\author{
Wojciech Moćko ${ }^{1}$ and Leopold Kruszka ${ }^{2, a}$ \\ ${ }^{1}$ Motor Transport Institute, 80, Jagiellońska st., 03-301 Warsaw, Poland \\ ${ }^{2}$ Gen. Jaroslaw Dabrowski Military University of Technology, 2, Gen. Sylwester Kaliski st., 00-908 Warsaw, Poland
}

\begin{abstract}
Currently, the computer programs of CAD type are basic tool for designing of various structures under impact loading. Application of the numerical calculations allows to substantially reduce amount of time required for the design stage of such projects. However, the proper use of computer aided designing technique requires input data for numerical software including elastic-plastic models of structural materials. This work deals with the constitutive model developed by Rusinek and Klepaczko (RK) applied for the modelling of mechanical behaviour of selected grades structural St0S, St3SX, 18GS and 34GS steels and presents here results of experimental and empirical analyses to describe dynamic elastic-plastic behaviours of tested materials at wide range of temperature. In order to calibrate the RK constitutive model, series of compression tests at wide range of strain rates, including static, quasi-static and dynamic investigations at lowered, room and elevated temperatures, were carried out using two testing stands: servo-hydraulic machine and split Hopkinson bar. The results were analysed to determine influence of temperature and strain rate on visco-plastic response of tested steels, and show good correlation with experimental data.
\end{abstract}

\section{Introduction}

In practical applications the cases of extreme loadings of building structure may be also considered, i.e. fire, earthquake or threats related to terrorism [1]. The last one are appears in recent years and may take a form of detonations and blast loadings or impact of large objects into building [2,3]. Since the mechanical properties of structural materials strongly depends on temperature and strain rate, therefore it is justifiable to take into account those relations during calculations [4]. Moreover, knowing precise material characteristics the FEM simulation of building behaviour under sudden impulse loadings of may by conducted.

This work deal with the constitutive model developed by Rusinek and Klepaczko (RK) applied for the modelling of mechanical behaviour of selected grades structural St0S, St3SX, 18GS and 34GS building steels and presents here results of experimental and empirical analyses to describe elastic-plastic behaviours of tested materials. In order to calibrate the RK constitutive model, series of compression tests at wide range of strain rates, including static, quasistatic and dynamic investigations at lowered, room and elevated temperatures, were carried out using two testing stands: servo-hydraulic machine and split Hopkinson bar. The results were analysed to determine influence of temperature and strain rate on visco-plastic response of tested steels, and show good correlation with experimental data.

Chemical composition of steels being analysed is presented in Table 1.

\footnotetext{
${ }^{a}$ Corresponding author: 1 kruszka@wat.edu.pl
}

Table 1. Chemical composition of selected structural steels [5].

\begin{tabular}{|c|c|c|c|c|c|c|c|c|c|}
\hline $\begin{array}{l}\text { Steel } \\
\text { class } \\
\text { Grade }\end{array}$ & $\begin{array}{l}\mathrm{C} \\
\max \\
{[\%]}\end{array}$ & $\begin{array}{l}\mathrm{Si} \\
\max \\
{[\%]}\end{array}$ & $\begin{array}{l}\mathrm{P} \\
\max \\
{[\%]}\end{array}$ & $\begin{array}{l}\mathrm{S} \\
\max \\
{[\%]}\end{array}$ & $\begin{array}{l}\mathrm{M} \\
\max \\
{[\%]}\end{array}$ & $\begin{array}{l}\mathrm{Cr} \\
\max \\
{[\%]}\end{array}$ & $\begin{array}{l}\mathrm{Ni} \\
\max \\
{[\%]}\end{array}$ & $\begin{array}{l}\mathrm{Cu} \\
\max \\
{[\%]}\end{array}$ & $\begin{array}{l}\text { Mo } \\
\max \\
{[\%]}\end{array}$ \\
\hline $\begin{array}{l}\text { A-0 } \\
\text { St0S-b }\end{array}$ & 0.23 & 0.40 & 0.07 & 0.06 & 1.0 & - & - & - & - \\
\hline $\begin{array}{l}\text { A-I } \\
\text { St3SX }\end{array}$ & 0.22 & 0.07 & 0.05 & 0.05 & - & - & - & - & - \\
\hline $\begin{array}{l}\text { A-II } \\
18 G 2\end{array}$ & 0.22 & 0.55 & 0.05 & 0.05 & 1.5 & 0.3 & 0.3 & 0.35 & 0.1 \\
\hline $\begin{array}{l}\text { A-III } \\
34 G S\end{array}$ & 0.22 & 0.70 & 0.07 & 0.05 & 1.2 & 0.3 & 0.3 & 0.35 & 0.1 \\
\hline
\end{tabular}

\section{Analysis of visco-plastic response of structural steels}

In order to obtain stress-strain curves of selected steels at various temperatures, i.e. lowered and elevated ones, two various experimental methods were applied using thermal chambers. At low strain rate compression tests were conducted using a servo-hydraulic testing machine. An electro-mechanical extensometer was applied for the axial strain measurements. The specimens used in all of the tests performed were machined from round bars using the machining. Interfaces were lubricated using $\mathrm{MoS}_{2}$ in order to reduce friction effects between the anvil and the specimen under compression.

At high strain rates well-known Split Hopkinson Pressure Bar methodology was applied. The signals acquired from the strain gauges were amplified by the wideband bridge circuit and digitized by an oscilloscope. The initial velocity of the striker, which was accelerated in

This is an Open Access article distributed under the terms of the Creative Commons Attribution License 4.0, which permits unrestricted use, distribution, and reproduction in any medium, provided the original work is properly cited. 


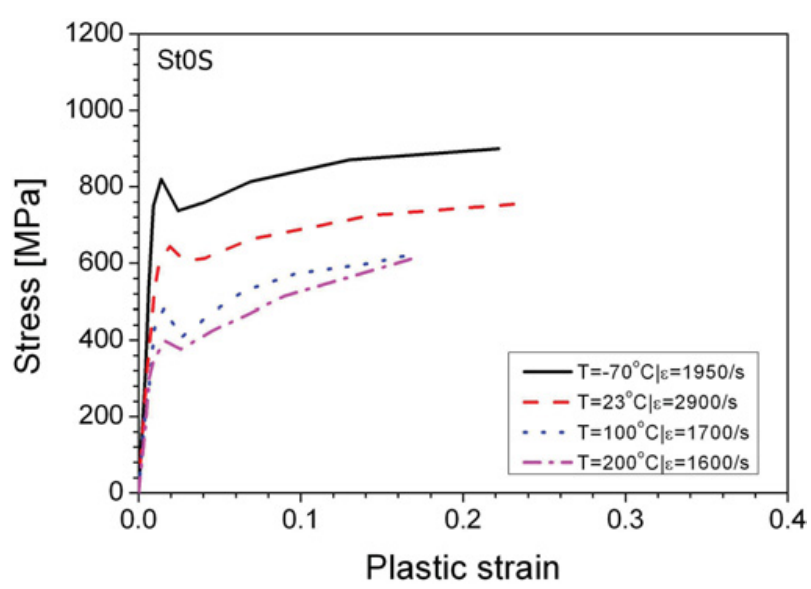

Figure 1. Dynamic stress-strain curves of StOS steel at wide range of temperatures.

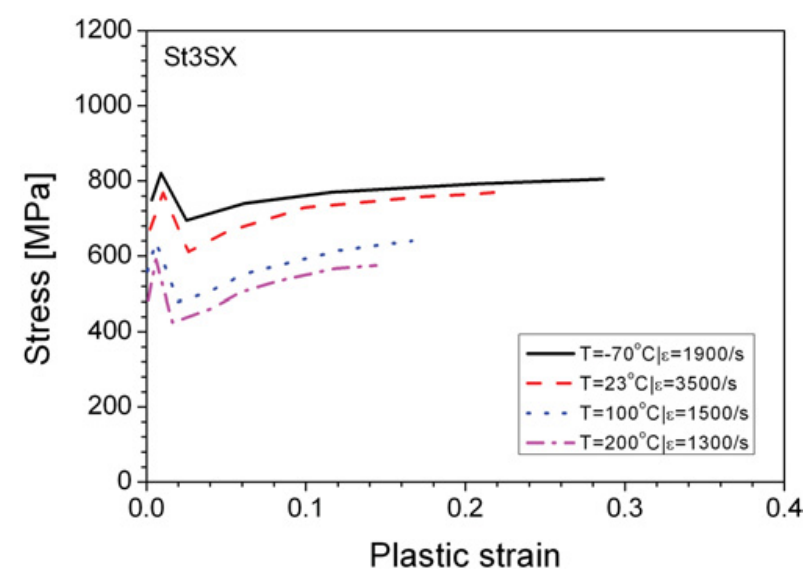

Figure 2. Dynamic stress-strain curves of St3SX steel at wide range of temperatures.

a pressure gas launcher was measured by two sets of diodes and photo detectors coupled to a digital counter. Based on the waveforms recorded by a digital oscilloscope for transmitted $\varepsilon_{T}(t)$ and reflected $\varepsilon_{R}(t)$ waves and the known cross sectional area of the bars $\mathrm{A}$ and the specimen $\mathrm{A}_{S}$, the speed of the elastic wave propagation in the material of the bars $C_{0}$ and the test-piece length $L$, it is possible to determine stress $\sigma(t)$, strain $\varepsilon(t)$ and strain rate $\dot{\varepsilon}(t)$ in the specimen using the following formulas:

$$
\begin{gathered}
\sigma(t)=E\left(\frac{A}{A_{S}}\right) \varepsilon_{T}(t) \\
\varepsilon(t)=-\frac{2 C_{0}}{L} \int \varepsilon_{R}(t) d t \\
\dot{\varepsilon}(t)=\frac{d \varepsilon(t)}{d t}=\frac{-2 C_{0}}{L} \varepsilon_{R}(t) .
\end{gathered}
$$

The dynamic stress-strain characteristics of St0S, St3SX, $18 \mathrm{GS}$ and $34 \mathrm{GS}$ steels obtained at wide range of temperatures are presented in Figs. 1-4. The shape of curves for different steel grades is similar, however clearly visible differences in flow stress magnitude may be found. All tested grades of steel shows strong strain hardening

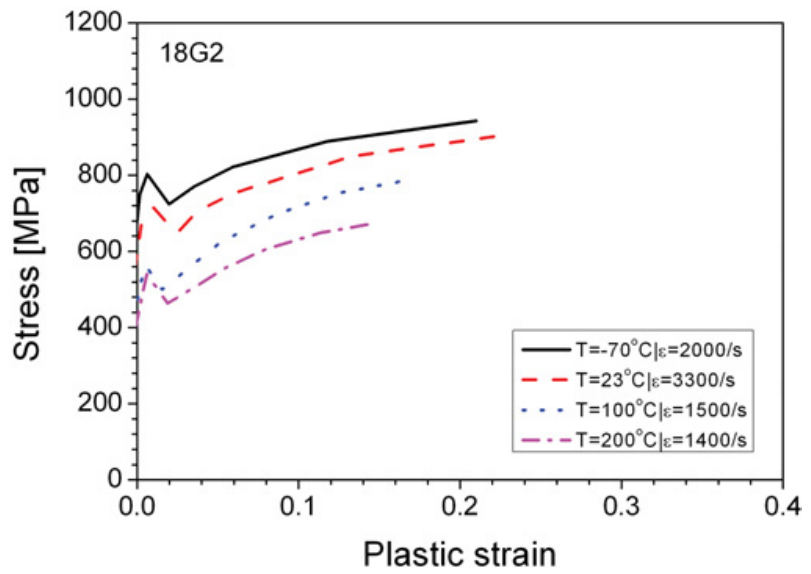

Figure 3. Dynamic stress-strain curves of $18 \mathrm{G} 2$ steel at wide range of temperatures.

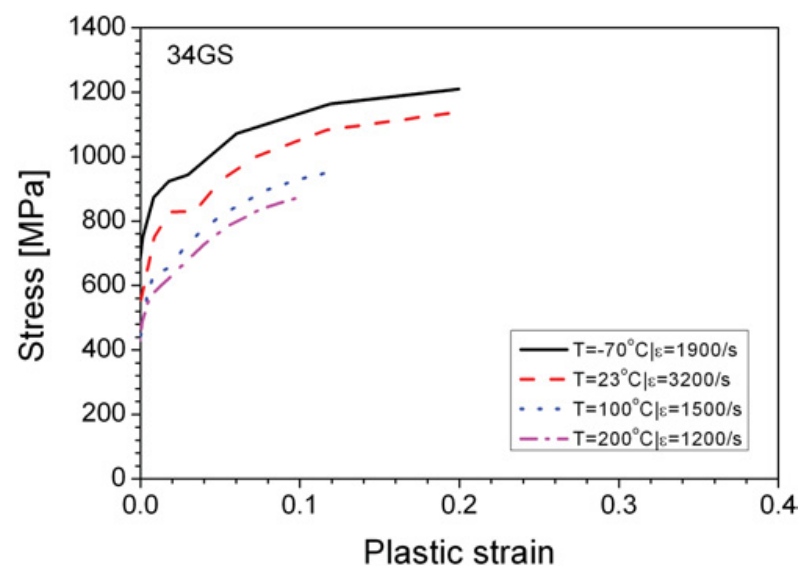

Figure 4. Dynamic stress-strain curves of 34GS steel at wide range of temperatures.

effect, which may be observed as an increase of flow stress in a function of strain. The second mechanism which may be observed is strain rate hardening. It may be found that nature of flow stress increase in a function of strain rate is similar for all steel grades.

\section{The Rusinek-Klepaczko constitutive model}

The overall flow stress is decomposed into three stress components [6]: the internal stress $\bar{\sigma}_{\mu}\left(\bar{\varepsilon}^{p}, \dot{\bar{\varepsilon}}^{p}, T\right)$, the effective stress $\bar{\sigma}^{*}\left(\dot{\bar{\varepsilon}}^{p}, T\right)$ and the drag stress $\bar{\sigma}_{d}\left(\dot{\bar{\varepsilon}}^{p}\right)$, as shown in Eq. (4).

$$
\begin{aligned}
& \bar{\sigma}\left(\bar{\varepsilon}_{p}, \overline{\dot{\varepsilon}}_{p}, T\right)= \\
& \frac{E(T)}{E_{0}}\left[\sigma_{\mu}\left(\bar{\varepsilon}_{p}, \overline{\dot{\varepsilon}}_{p}, T\right)+\sigma^{*}\left(\overline{\dot{\varepsilon}}_{p}, T\right)\right]+\bar{\sigma}_{d}\left(\dot{\bar{\varepsilon}}_{p}\right) .
\end{aligned}
$$

Because the Young's modulus is temperature dependent, it has the form shown in Eq. (5).

$$
\mathrm{E}(\mathrm{T})=\mathrm{E}_{0}\left\{1-\frac{\mathrm{T}}{\mathrm{T}_{\mathrm{m}}} \exp \left[\theta^{*}\left(1-\frac{\mathrm{T}}{\mathrm{T}_{\mathrm{m}}}\right)\right]\right\}
$$

where $E_{0}, T_{m}$ and $\theta^{*}$ denote the Young's modulus at $T=0 \mathrm{~K}$, the melting temperature and the characteristic 
homologous temperature, respectively. This expression allows the definition of the material thermal softening as a function of the crystal lattice [7], and empirically demonstrates the influence of the material structure on the temperature sensitivity.

The internal stress $\sigma_{\mu}\left(\bar{\varepsilon}_{p}, \bar{\varepsilon}_{p}, T\right)$ is defined by a powerlaw type phenomenological function shown in Eq. (6).

$$
\bar{\sigma}_{\mu}\left(\bar{\varepsilon}^{p}, \dot{\bar{\varepsilon}}^{p}, T\right)=B\left(\dot{\bar{\varepsilon}}^{p}, T\right)\left(\varepsilon_{0}+\bar{\varepsilon}^{p}\right)^{n\left(\dot{\bar{\varepsilon}}^{p}, T\right)}
$$

where $B\left(\dot{\bar{\varepsilon}}^{p}, T\right)$ and $n\left(\dot{\bar{\varepsilon}}^{p}, T\right)$ are the modulus of plasticity and the strain hardening exponent, respectively, both of which are rate- and temperature-dependent, and is the strain level that defines the material yield stress at a specific strain rate and temperature.

The explicit formulations describing the modulus of plasticity $B\left(\dot{\bar{\varepsilon}}^{p}, T\right)$ and the strain hardening exponent $n\left(\dot{\bar{\varepsilon}}^{p}, T\right)$ are given in Eqs. (7)-(8).

$$
\begin{gathered}
B\left(\dot{\bar{\varepsilon}}^{p}, T\right)=B_{0}\left(\left(\frac{T}{T_{m}}\right) \log \left(\frac{\dot{\varepsilon}_{\text {max }}}{\dot{\bar{\varepsilon}}^{p}}\right)\right)^{-v} \\
n\left(\dot{\bar{\varepsilon}}^{p}, T\right)=n_{0}\left\langle 1-D_{2}\left(\frac{T}{T_{m}}\right) \log \left(\frac{\dot{\bar{\varepsilon}}^{p}}{\dot{\varepsilon}_{\text {min }}}\right)\right\rangle
\end{gathered}
$$

where $B_{0}$ is a material parameter, $v$ defines the temperature sensitivity, $n_{0}$ is the strain hardening exponent at $\mathrm{T}=$ $0 \mathrm{~K}, D_{2}$ is a material constant and $\dot{\varepsilon}_{\text {min }}$ is the lower limit of the model. The McCauley operator has the following properties: $\langle\bullet\rangle=\bullet$ if $\langle\bullet\rangle \geq 0$, or $\langle\bullet\rangle=0$ if $\langle\bullet\rangle \leq 0$.

The effective stress $\sigma *\left(\overline{\dot{\varepsilon}}_{p}, T\right)$, defined in Eq. (4), is derived from the concept of a thermal activation analysis. It describes the combined effects of the strain rate and temperature on plastic flow, and it is defined to be independent of strain [8].

$$
\bar{\sigma}^{*}\left(\dot{\bar{\varepsilon}}^{p}, T\right)=\sigma_{0}^{*}\left\langle 1-D_{1}\left(\frac{T}{T_{m}}\right) \log \left(\frac{\dot{\varepsilon}_{\text {max }}}{\dot{\bar{\varepsilon}}^{p}}\right)\right\rangle^{m^{*}}
$$

where $\bar{\sigma}^{*}$ is a material parameter related to the threshold thermal stress, $D_{1}$ is a material constant, $\dot{\varepsilon}_{\max }$ is the maximum strain rate accepted for a particular material and $m^{*}$ is a constant that determines the rate and temperature dependences of the material flow stress.

The drag stress $\bar{\sigma}_{d}\left(\dot{\bar{\varepsilon}}_{p}\right)$ is defined by Eq. (10). This formulation, originally developed by Nemat-Nasser [9], provides a phenomenological description of the ratedependent strain within the viscous drag regime [7].

$$
\bar{\sigma}_{d}\left(\dot{\bar{\varepsilon}}^{p}\right)=\chi \cdot\left[1-\exp \left(-\alpha \cdot \dot{\bar{\varepsilon}}^{p}\right)\right]
$$

where $\chi$ and $\alpha$ are constants that represent the material rate sensitivity caused by the drag resistance to dislocation motion.

In the case of adiabatic conditions of deformation, the constitutive relation is combined with the energy balance principle, as shown in Eq. (11). This relation allows for an approximation of the thermal softening of the material via adiabatic heating.

$$
\Delta T\left(\bar{\varepsilon}^{p}, \bar{\sigma}\right)=\frac{\beta}{\rho C_{p}} \int_{0}^{\bar{\varepsilon}^{p}} \bar{\sigma}\left(\bar{\varepsilon}^{p}, \dot{\bar{\varepsilon}}^{p}, T\right) d \bar{\varepsilon}^{p}
$$

Table 2. RK model coefficient for analysed structural steels.

\begin{tabular}{l|l|l|l|l|l|l|l|l}
\hline $\begin{array}{l}\text { Steel class } \\
\text { Grade }\end{array}$ & $\theta$ & $\mathrm{B}_{0}$ & $v$ & $\sigma_{0}$ & $\mathrm{D}_{1}$ & $\mathrm{~m}$ & $\mathrm{n}_{0}$ & $\mathrm{D}_{2}$ \\
\hline $\begin{array}{l}\text { A-0 } \\
\text { St0S-b }\end{array}$ & 0.9 & 845 & 0.01 & 1200 & 0.50 & 3.4 & 0.28 & 0.10 \\
$\begin{array}{l}\text { A-I } \\
\text { St3SX }\end{array}$ & 0.9 & 797 & 0.02 & 1100 & 0.53 & 2.8 & 0.28 & 0.05 \\
A-II & 0.9 & 927 & 0.01 & 1000 & 0.53 & 2.7 & 0.24 & 0.01 \\
$\begin{array}{l}\text { 18G2 } \\
\text { A-III }\end{array}$ & 0.9 & 1200 & 0.05 & 1500 & 0.53 & 3.4 & 0.21 & 0.01 \\
34GS & & & & & & & & \\
\hline
\end{tabular}

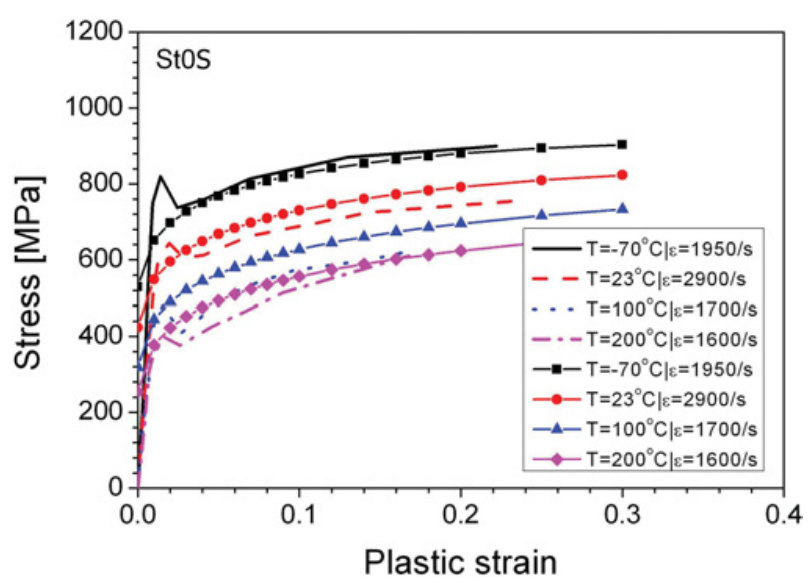

Figure 5. Comparison of experimental and RK model dynamic stress-strain curves at wide range of temperatures based data of St0S steel.

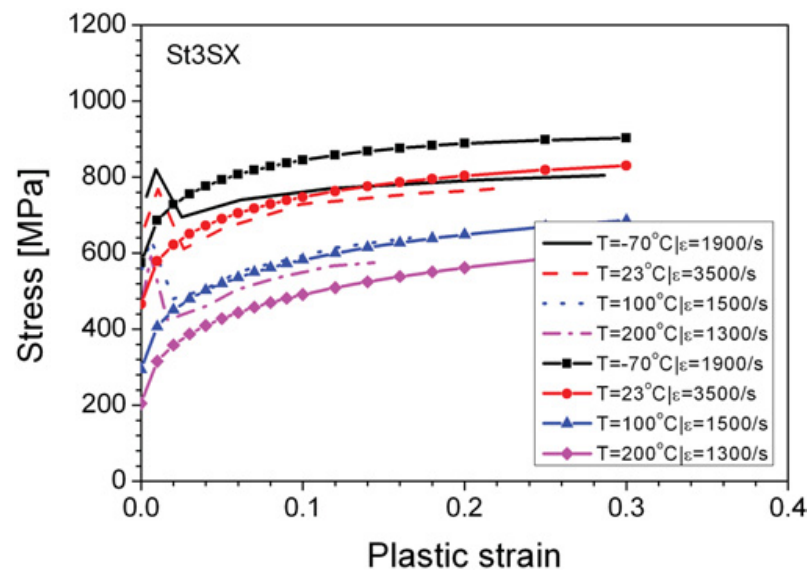

Figure 6. Comparison of experimental and RK model dynamic stress-strain curves at wide range of temperatures based data of St3SX steel.

where $\beta$ is the Quinney-Taylor coefficient, which is assumed to be constant, $\rho$ is the material density and $C_{p}$ is the specific heat at a constant pressure. The transition from isothermal to adiabatic conditions is assumed to occur at $\overline{\dot{\varepsilon}}_{p}=10 \mathrm{~s}^{-1}$, in agreement with experimental observations and numerical estimations reported in the literature [10]. The RK model coefficients obtained according to calibration procedure described in details previously [11] are presented in Table 2 .

The dynamic stress-strain curves obtained experimentally and calculated on the basis of RK equation at wide 


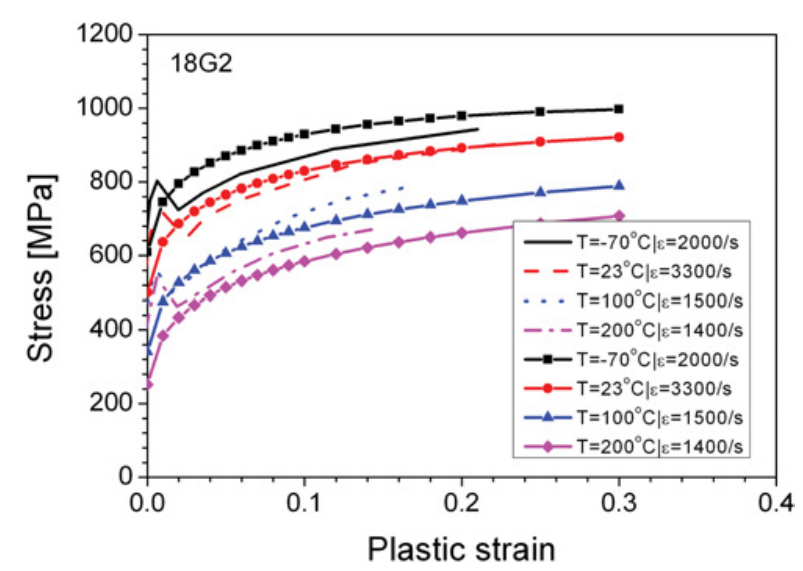

Figure 7. Comparison of experimental and RK model dynamic stress-strain curves at wide range of temperatures based data of $18 \mathrm{G} 2$ steel.

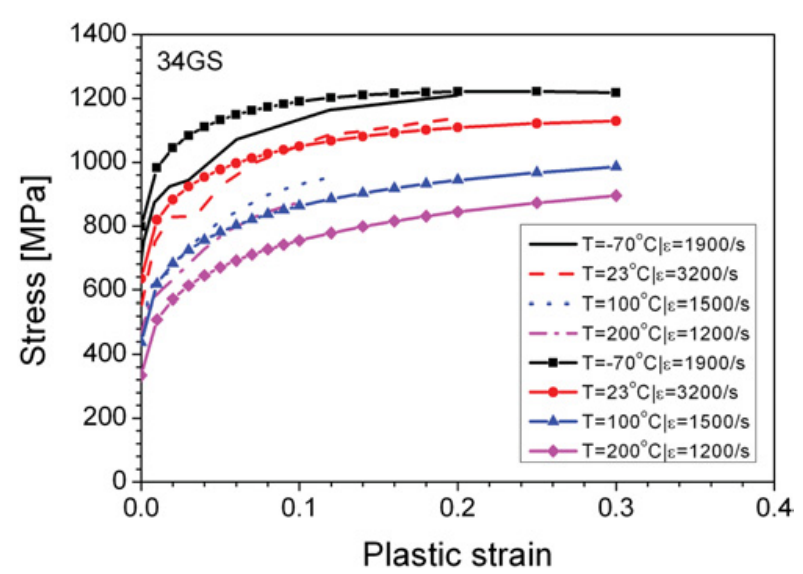

Figure 8. Comparison of experimental and RK model dynamic stress-strain curves at wide range of temperatures based data of 34 GS steel.

range of temperatures are presented in Figs. 5-8. For all analyzed cases model based data shows reasonable agreement with experimental ones at lowered, room and elevated temperatures as well.

\section{Summary}

The viscous-plastic characteristics of St0S, St3SX, 18 GS and $34 \mathrm{GS}$ steels depends on temperature and strain rate. Therefore it is strongly recommended to take those relations into consideration in the case of numerical analysis of building behavior under extreme loading conditions i.e. fire, earthquake, blast or impact of building objects. The elasto-plastic behavior of structural steel may be expressed in a form of Rusinek-Klepaczko constitutive equation, which shows good correlation with experimental data.

\section{References}

[1] L. Kruszka, R. Rekucki, Applied Mechanics and Materials 82, 422 (2011)

[2] V. G. Bazhenov, A I. Kibetz, L. Kruszka, International Journal of Protective Structures 3, 449 (2012)

[3] M. V. Chernobryvko, Y. S. Vorobyov, L. Kruszka, International Journal of Protective Structures 3, 141 (2012)

[4] W. Mocko, J.A. Rodriguez-Martinez, Z.L. Kowalewski, A. Rusinek. Strain 48, 498 (2012)

[5] W. Moćko, L. Kruszka, Procedia Engineering 57, 789 (2013)

[6] A. Rusinek, J. R. Klepaczko, International Journal of Plasticity 17, 87 (2001)

[7] A. Rusinek, J.A. Rodriguez-Martimez, J.R. Klepaczko, R.B. Pecherski, Materials \& Design 30, 1748 (2009)

[8] S. Nemat-Nasser, W.G. Guo, V.F. Nesterenko, Mechanics of Materials 33, 425 (2001)

[9] R. Kapoor, S. Nemat-Nasser, Metallurgical and Materials Transactions A31, 815 (1999)

[10] O. Oussouaddi, J.R. Klepaczko, Journal de Physique IV 1, 323 (1991).

[11] A. Rusinek, J.A. Rodriguez-Martinez, A. Arias, International Journal of Mechanical Sciences 52, 120 (2010) 